\title{
Plástico na Era do Coronavírus: de Herói a Vilão, de Vilão a Coroado
}

$>$ Maria Elvira Callapez

\begin{abstract}
Plastic in the coronavirus era: from hero to villain, from villain to crowned. Plastics are considered a symbol of technological progress and of industrial growth. They soon became products of great consumption, providing us with a more comfortable and safer lifestyle. Plastics are everywhere and although they offer great advantages, they are also environmentally persistent, which raised some problems. Most plastics used today are not biodegradable, a problem worsened by the fact of non-recycled plastics sent to landfills or simply disposed in the environment. With the outbreak of COVID-19, single-use plastics that, in recent years, have been the focus of environmental concerns, are now at the forefront of fighting this pandemic to prevent the spread of the SARS-CoV-2 virus. This essay gives visibility to plastics that re(assume) their functionality in a very significant contribution to the containment of the corona virus.
\end{abstract}

Os plásticos, considerados um símbolo do progresso tecnológico e do crescimento da indústria, desde cedo se tornaram produtos de grande consumo, proporcionando-nos um estilo de vida mais confortável e seguro. Os plásticos estão por toda a parte e, embora ofereçam grandes vantagens, são também ambientalmente persistentes, o que tem levantado alguns problemas.

A maioria dos plásticos usados atualmente não é biodegradável, um problema que é agravado pelo facto de alguns plásticos não serem reciclados, sendo em vez disso encaminhados para aterros sanitários ou simplesmente descartados no meio ambiente. Com o surto da COVID-19, os plásticos de utilização única que, nos últimos anos, têm estado na mira das preocupações ambientais, estão agora na linha de frente da luta contra essa pandemia para impedir a propagação do vírus SARS-CoV-2. Este ensaio dá visibilidade aos plásticos que re(assumem) a sua funcionalidade numa contribuição muito significativa para a contenção deste vírus.

\footnotetext{
Introdução

O plástico, o material que tanto fascinou o filósofo francês Roland Barthes (1915-1980), descrito no seu livro Mythologies em 1957, tornou-se involuntariamente um símbolo da crise da nossa sociedade pós-moderna e um dos maiores desafios do século XXI [1].

A palavra "Plástico" é usada, frequentemente, num contexto negativo. Tem havido uma retórica alarmista contra os plásticos, uma "PLASTICOFOBIA". Notícias e manchetes sobre o efeito dos plásticos nas mudanças climáticas e dos microplásticos nos
}

oceanos e nos ambientes de águas superficiais, o seu impacto na vida marinha e humana, são ocorrências praticamente diárias nos meios de comunicação social. Imagens de animais marinhos enleados em resíduos de plástico, ilhas de plástico a flutuar nos oceanos e resíduos de plástico espalhados pelas nossas cidades, catalisaram a recente onda de mobilização emocional contra os plásticos.

Muito destes sentimentos resultam de alguma confusão entre o significado de poluição e de resíduos. 
A maior parte da poluição é causada pela queima de combustíveis fósseis, como petróleo, carvão ou gás natural, o que aumenta a quantidade de dióxido de carbono na atmosfera e o consequente efeito de estufa. Os plásticos, por si, não poluem o meio ambiente, não são os causadores destes acontecimentos, que resultam da colocação do "lixo" plástico em lugares inapropriados, sem preocupações evidentes para uma seleção adequada dos materiais. Muito recentemente a Direção-Geral de Saúde (DGS) alertou para o cumprimento de regras de proteção ambiental, nomeadamente para a colocação das máscaras descartáveis e luvas, usadas no contexto da COVID-19, no lixo doméstico e não no ecoponto, e nunca na via publica, como é comumente observado atualmente, local totalmente inadequado ao seu destino final (Figura 1).

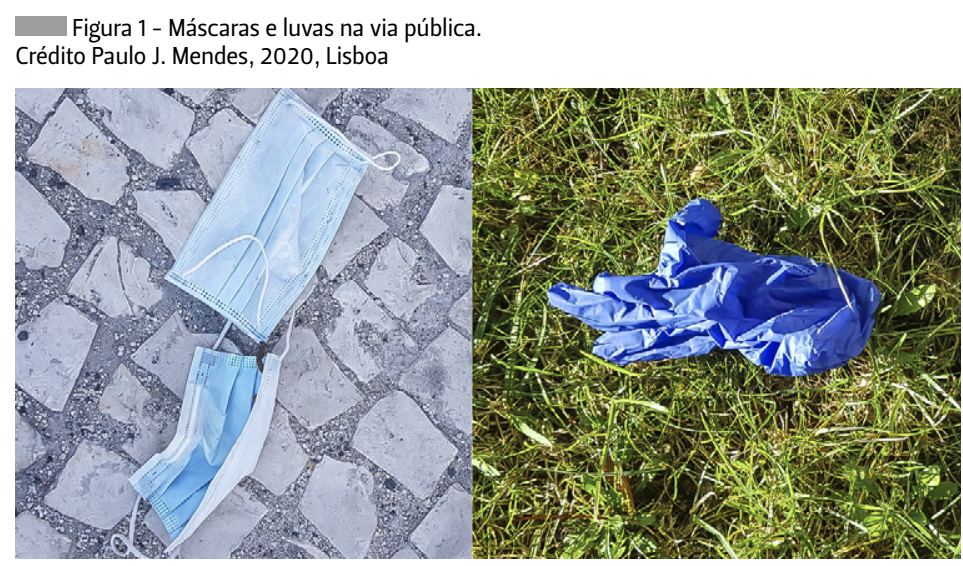

É importante um consumo responsável para que a utilização dos plásticos se justifique e evitar que os oceanos, por exemplo, recebam estes materiais como resíduos. Para os movimentos "anti-plástico", estes materiais, nomeadamente os sacos de plástico, são perigosos e desagradáveis além de constituírem uma ameaça ambiental. Todavia não são eles os culpados por esgotos entupidos, rios e animais marinhos asfixiados ou pelo aquecimento global. Em vez disso, são provavelmente a nossa melhor aposta para transportar todo o nosso lixo de forma consciente. 0 plástico tem um papel muito significativo na redução das mudanças climáticas, conforme facilmente se evidencia, pois economiza energia, reduz emissões de $\mathrm{CO}_{2}$, e conserva recursos, entre outros fatores. É vital para a indústria alimentar, promovendo a sua sustentabilidade, contribuindo para a redução do desperdício de alimentos, aumentando a vida útil dos produtos e evitando a deterioração dos mesmos. No sector dos transportes, os plásticos, menos densos que os materiais convencionais, diminuem o peso dos veículos (carros, camiões, aviões, barcos, ...) e consequentemente o consumo de combustível. Representam aproximadamente $60 \%$ dos materiais utilizados no fabrico de têxteis, um total de mais de 70 milhões de toneladas de plástico produzido anualmente, o que reduz a necessidade de fibras naturais, como algodão ou lã, que exigem grandes áreas de terra produtiva e de água. Estes materiais são fundamentais nos equipamentos de produção de energia renovável, como são exemplos as pás de turbinas eólicas, pás de moinhos de maré e tanques de biogás [2].

Os plásticos, materiais especiais, símbolos da modernidade, entraram definitivamente nas nossas vidas porque se impuseram pelas suas propriedades únicas: são baratos, leves, duráveis, resistentes à corrosão, bons isoladores térmicos e elétricos, versáteis, feitos por medida. São tecnicamente sofisticados e aplicam-se em quase todos os sectores da nossa sociedade: medicina, eletrónica, aeronáutica, indústria automóvel, telecomunicações, construção, alimentação, vestuário, calçado, entre outras.

Os plásticos são polímeros [3], (mas nem todos os polímeros são plásticos), macromoléculas [4], de elevado peso molecular, constituídos a partir de moléculas menores, os monómeros, que estabelecem liğações químicas entre si, através de reações de condensação ou de polimerização de adição. Os plásticos incluem-se na classe de polímeros sintéticos que passam pelo estado plástico, ou seja, um estado moldável entre o estado líquido e o estado sólido, a uma temperatura superior à temperatura ambiente (considerar pressão e temperaturas normais, PTN). Estes materiais deformam-se sob a ação da temperatura e de uma força exterior e conservam essa deformação depois destes agentes deixarem de atuar.

Com base nas características químicas, nomeadamente, a estrutura e as forças intermoleculares envolvidas, distinguem-se dois grupos de plásticos: os termoplásticos e os termoendurecíveis, termoestáveis ou termofixos, ainda que esta classificação levante problemas [5], dado que pode abranger uma gama de polímeros mais ou menos extensa e diversificada. Quando os plásticos se formam, as suas moléculas emaranham-se como "esparguete" e a sua resistência mecânica depende muito da forma como as moléculas estão interligadas. Assim, os termoplásticos são polímeros de peso molecular muito elevado, flexíveis a temperaturas elevadas [6-8]. Por conseguinte, podem ser moldados plasticamente tantas vezes quantas necessárias, voltando ao estado sólido depois de arrefecidos. Neste tipo de plásticos existem ligações covalentes intensas entre os átomos de cada cadeia, mas as forças entre as cadeias emaranhadas são fracas, permitindo que estas se movam facilmente 
umas sobre as outras. É esta estrutura que lhes confere as propriedades atrás referidas (Figuras 2 e 3 ). São exemplos de termoplásticos o polietileno (PE), o poliestireno (PS), o polipropileno (PP), o policloreto de vinilo (PVC), os acrílicos e o «nylon»».

Figura 2 - Representação dos termoplásticos.

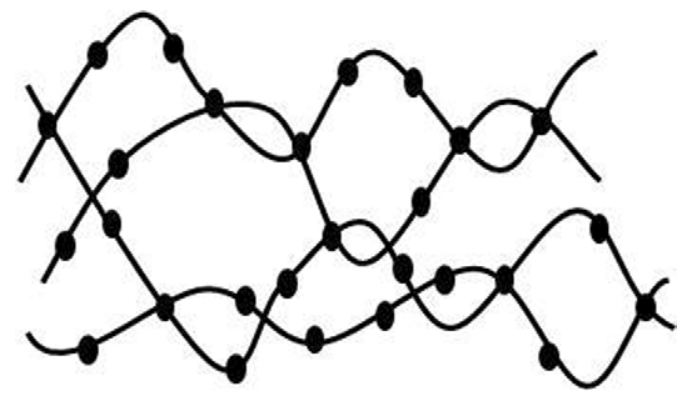

Figura 3 - Representação da deformação dos termoplásticos.

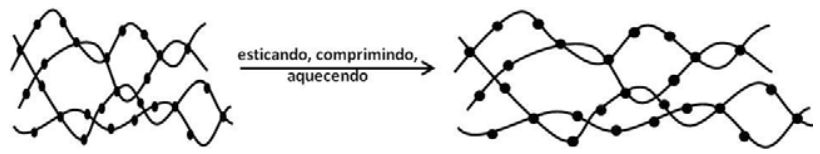

Os polímeros termoendurecíveis tornam-se rígidos durante o seu processo de fabrico e moldagem a quente. Solidificam formando um corpo sólido muito estável, o que impede o reprocessamento inverso para posterior reutilização. Portanto, não podem ser novamente transformados, i. e., amolecidos e moldados. Na sua forma original são rígidos e decompõem-se ao serem aquecidos acima de uma determinada temperatura. Nos polímeros com esta designação existem ligações covalentes intensas entre os átomos de cada cadeia e entre as próprias cadeias. Por isso elas não se movem umas relativamente às outras quando aquecidas (Figuras 4 e 5). São exemplos destes polímeros termoendurecíveis a «baquelite», a

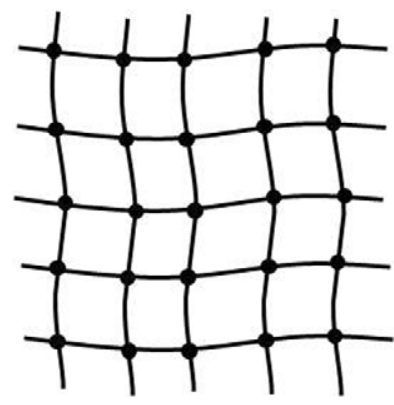

Figura 5 - Representação dos polímeros termoendurecíveis sob ações mecânicas e térmicas.
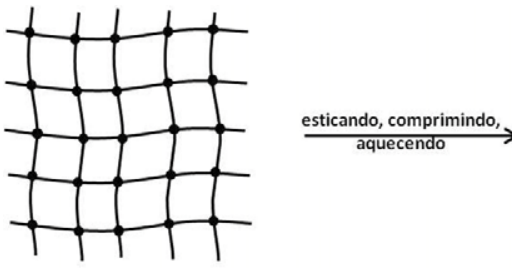
aquecendo

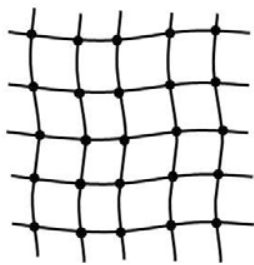

resina ureia-formaldeído, as resinas epóxi, a borracha vulcanizada e alguns poliuretanos.

Há ainda outro tipo de polímeros com bastante elasticidade que se denominam por elastómeros. Têm a característica de se alongarem várias vezes, quando submetidos a uma força mecânica, e de voltarem à sua forma inicial quando esta força deixa de atuar. São exemplos de elastómeros as borrachas (Figura 6).

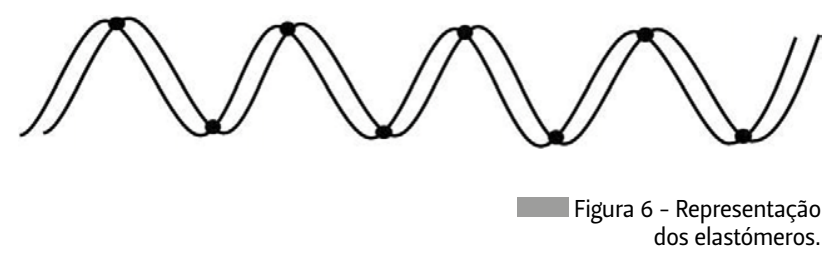

A diversidade de polímeros e a versatilidade das suas propriedades mecânicas e térmicas facilitam a produção de uma vasta gama de produtos de plástico que trazem avanços tecnológicos, economia de energia e inúmeros outros benefícios sociais. É um dos materiais mais utilizados no mundo, adequados a um amplo espectro de usos. São vistos como um material milagroso, exemplo excecional de engenharia, assumindo o status único de um material indispensável para o estilo de vida moderno. De facto, os plásticos conquistaram o planeta e o seu uso é inevitável no nosso quotidiano (Figura 7).

Figura 7 - Plásticos do quotidiano. Crédito: M.E. Callapez, 2019, Berkeley (Esq.); 2020, Lisboa, coleção M.E. Callapez (Dir.)

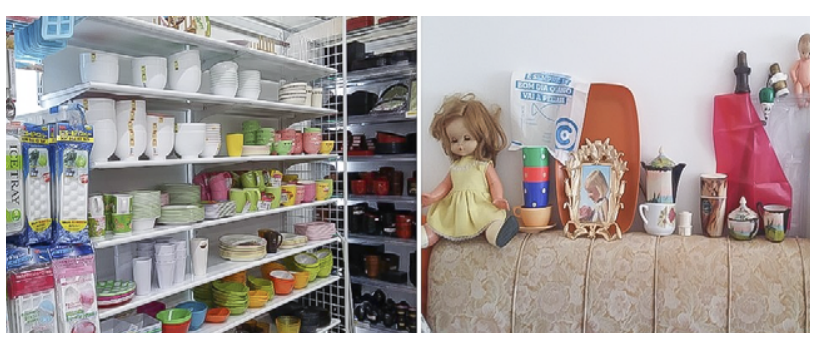


O "plástico" acaba por ser vítima do seu próprio sucesso, o herói de ontem, o vilão de hoje. Mas, parece que por ironia, em algumas semanas, a imagem do plástico volta a ser positiva e a indústria química associada ao fabrico destes materiais "respira" com alívio do cenário que viria a ser o seu annus horribilis em virtude do início da proibição dos plásticos de uso único. Tal mudança deve-se à chegada do coronavírus que se espalhou por todo o mundo em 2020.

\section{Os plásticos e a COVID-19}

A doença COVID-19, causada pelo vírus SARS-CoV-2, surgiu no final de 2019 e em seis meses já infetou mais de oito milhões e meio de pessoas e matou mais do que quatrocentas e cinquenta mil (infetados: 8509393 e mortes: 454380) [9]. A doença propaga-se de pessoa para pessoa, pelo ar, através de gotículas projetadas da boca ou do nariz quando a pessoa infetada tosse ou espirra, podendo outra ser infetada se inalar essas gotículas ou se tocar em superfícies contaminadas.

A crise da COVID-19 tem destacado o papel essencial dos plásticos, sendo um dos efeitos da pandemia a procura acentuada por estes produtos em defesa do público em geral, pacientes, profissionais de saúde e serviços [10]. De facto, os plásticos têm estado na linha de frente na luta contra a pandemia da COVID-19, desempenhado um papel fundamental na assistência médica para a prevenção da doença. Têm cada vez mais procura os equipamentos de proteção individual (EPI's) de uso único, tais como máscaras, batas, óculos, luvas, botas, seringas, tubos intravenosos, zaragatoas, cateteres, fabricados com diferentes polímeros usados por equipas médicas e enfermeiros para evitar a disseminação e infeção por bactérias e vírus mortais e reduzir o risco dos pacientes [11]. É ainda importante referir que todos estes equipamentos de proteção individual e utensílios auxiliares de diagnóstico são igualmente responsáveis por uma grande quantidade de resíduos, infelizmente nem sempre com o destino final adequado, como se referiu acima.

Um dos EPI's em destaque e fundamental nesta pandemia é a máscara para evitar contacto entre o ar que se respira e a boca e o nariz. Uma máscara cirúrgica é constituída por tecido não tecido (TNT), que possui melhor capacidade de filtração e de permeabilidade ao ar, permanecendo menos escorregadio que o tecido. 0 material mais usado é o polipropileno, com 20 ou 25 gramas por metro quadrado $\left(\mathrm{g} / \mathrm{m}^{2}\right)$ de densidade. As máscaras também podem ser feitas de poliestireno, policarbonato, polietileno ou poliéster.

No meio da crise da COVID-19, é difícil evitar os plásticos descartáveis tendo em conta os seus benefícios para a saúde, higiene e segurança. Mas é importante mudar os maus costumes e até mudar a maneira como nos referimos aos produtos de uso único. Com efeito "As pessoas não devem dizer "produto plástico descartável" porque nada é descartável (...) não devem dizer "uso único" porque devemo-nos esforçar para usar tudo muitas vezes" [12]. Na realidade, alguns destes plásticos têm ciclos de vida útil, renováveis através de processos de reciclagem. Todavia, nesta gama de recicláveis, há que realçar que há produtos, como por exemplo as zaragatoas, que num ciclo de vida serão sempre de "uso único".

A escassez de EPI's, em muitos países, inspirou o recurso a modelos com artigos domésticos, como um saco plástico transparente colocado em volta das cabeças dos profissionais com um selo hermético ao redor do pescoço para proteção contra gotículas durante a intubação endotraqueal, em vez de óculos de proteção e máscara [13]. Neste caso, e se for utilizada esta proteção durante um longo período, estará em causa a própria vida do profissional de saúde uma vez que haverá um excesso de $\mathrm{CO}_{2}$ dentro do saco plástico. Uma seleção apropriada dos materiais constituintes das proteções individuais começa nos fabricantes com prioridade ao efeito protetor e ao tempo de utilização, mas com uma visão estratégica muito forte na reciclagem dos materiais envolvidos. No mundo dos polímeros há sem dúvida uma enorme versatilidade de possibilidades que, combinadas, possibilitem o fabrico de plásticos maioritariamente recicláveis. É aqui que reside a responsabilidade dos produtores a nível mundial num objetivo comum de diminuição e eliminação de resíduos desta natureza.

O coronavírus tem provocado debates sobre as embalagens de alimentos, onde alguns defendem que o plástico é vital para resguardo dos alimentos de germes e prolongamento da sua vida útil, enquanto outros salientam que a pandemia revela que o plástico descartável é insustentável e portador de substâncias nocivas e bactérias. Do ponto de vista da sustentabilidade, as embalagens plásticas superam as alternativas conforme têm provado vários estudos [14].

Na última década, as proibições de sacos de plásticos foram impostas em vários países. Mas agora, devido à pandemia de coronavírus, esses esforços de redução de plástico foram temporariamente suspensos devido a preocupações crescentes com a saúde. Embora se saiba que o coronavírus é transmitido principalmente por meio de interações pessoa a pessoa, não há certezas sobre se as embalagens podem transmitir a doença [15]. Em alguns países em vias de desenvolvimento, os sacos de plásticos servem de medida preventiva contra a propagação do novo coronavírus, como retrata a imagem de um homem que cobre as mãos com sacos de plástico, em Caracas (Figura 8). 


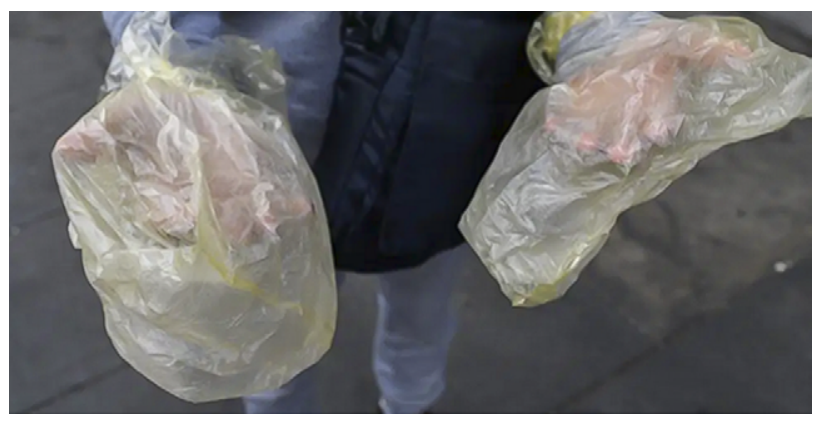

Figura 8 - Um homem cobre as mãos com sacos de plástico como medida preventiva contra a propagação do novo coronavírus, COVID-19, Caracas. Fotografia tirada em 20 de março de 2020 [16].

\section{Conclusões}

Com o aumento do uso de materiais plásticos no sector de saúde, seria recomendável que os consumidores, os governos e os reguladores e a indústria de plásticos se comprometessem a conviver com políticas e práticas corretas de recolha destes resíduos e que a reciclagem fosse um objetivo prioritário a fim de evitar a contaminação e a propagação da infeção por COVID-19 em benefício do planeta e das vidas humanas em perigo com esta doença.

\section{Referências}

[1] R. Barthes, "Mythologies", Éditions du Seuil, Manchecourt, 1957

[2] Disposable or single-use plastics? Neither! Recyclable or reusable plastics: www.expresspolymlett.com; https://doi.org/10.3144/ expresspolymlett.2020.1 (acedido em 19/05/2020)

[3] Polímero deriva das palavras gregas poli, que significa muitos, e meros, que significa unidades.

[4] Para uma discussão mais pormenorizada sobre nomenclatura de polímeros, ver: IUPAC. Pure Appl. Chem. 84 (2012) 2167-2169.

[5] H. A. Witcoff, B. G. Reuben, "Industrial Organic Chemicals in Perspective, Part Two: Technology, Formulation, and Use", John Wiley \& Sons, Nova lorque/Chichester/Brisbane/Toronto, 1980.

[6] P.F. Mastro, "Plastics Product Design", Scrivener Publishing LLC., John Wiley \& Sons, New Jersey, 2016.

[7] Understanding Plastics and Polymers - The Different Types of Plastic: https://www.azom.com/article. aspx? ArticlelD=17477 (acedido em 20/05/2020)

[8] Polymers and Plastics: https://www.azom.com/article aspx?ArticlelD=13567 (acedido em 14/05/2020)

\section{Maria Elvira Callapez}

É membro investigador no Centro Interuniversitário de História da Ciência e Tecnologia-Faculdade de Ciências, Universidade de Lisboa. Investigadora principal do projecto "O Triunfo da Baquelite - Contributos para uma História dos Plásticos em Portugal", ganhou em
2019 o Dibner Award for Excellence in Museum Exhibits, atribuído pela Society for the History of Technology (SHOT) pela exposição "Plasticidade - Uma História dos Plásticos em Portugal".

mecallapez@fc.ul.pt

ORCID.org/0000-0003-2461-363X.
No contexto da crise da pandemia em que vivemos, a higiene e a saúde do consumidor são uma prioridade pelo que o uso correto dos plásticos de uso único é crucial uma vez que, até ao momento, não há material alternativo comprovado e competitivo que supere os plásticos, os quais garantem a segurança e a limitação da contaminação.

O plástico é importante para o desenvolvimento sustentável e possui propriedades funcionais únicas que outros materiais não possuem. Em vez de bani-los, seria bom usá-los com responsabilidade, onde forem indispensáveis. A resposta que o plástico tem dado à crise do coronavírus, ao contribuir para a mitigação desta doença grave e contagiosa constitui, sem dúvida, um bom exemplo. Mas serão oportunas algumas questões: em tempos de pandemia pela COVID-19 o que seria do nosso planeta sem plásticos? Qual é a pegada de carbono correspondente ao fabrico destes plásticos? E quando será possível avaliar os resíduos de plásticos provenientes do combate e precaução a esta doença?

\section{Agradecimentos}

A autora agradece à equipa editorial do QUÍMICA os pertinentes comentários, sugestões e revisão do texto.

[9] Johns Hopkins University, Coronavirus Resource Center: https:// coronavirus.jhu.edu/ (acedido em 19/06/2020).

[10] J. J. Klemes, Y. V. Fan, R. R. Tan, P. Jiang, Renewable and Sustainable Energy Reviews 127 (2020) 1-7.

[11] Plastics Had Been Falling Out of Favor. Then Came the Virus: https://www. bloomberg.com/news/articles/2020-03-15/plastics-had-been-falling-outof-favor-then-came-coronavirus (acedido em 16/03/2020).

[12] Op. cit. [2].

[13] E. Lee, W. Loh, I. Ang, Y.Tan, J Emerg Med. 58 (2020) 821-823.

[14] P. R. Samanta, R. Gupta, R. Gupta, S. Chauhan, A. Johri, Ink World 26 (2020) 39-41.

[15] COVID-19 Sparks a Return of Plastic Bags: https://www.waste360.com/ plastics/covid-19-sparks-return-plastic-bags (acedido em 17/05/2020).

[16] Colby Cosh on COVID-19: How long before plastic bag haters feel safe to resume their crusade? https://nationalpost.com/opinion/colby-coshon-covid-19-how-long-before-plastic-bag-haters-feel-safe-to-resumetheir-crusade (acedido em 15/05/2020). 